Review article

\title{
Sustainable wood waste management in Nigeria
}

\author{
Jacob Mayowa Owoyemi ${ }^{1}$, Habeeb Olawale Zakariya ${ }^{1}$, Isa Olalekan Elegbede*2 \\ 1 Department of Forestry and Wood Technology, Federal University of Technology Akure, Ondo State, Nigeria \\ 2 Department of Environmental Planning, Brandenburg University of Technology, Cottbus-Senftenberg, Germany \\ E-mail address ( ${ }^{*}$ corresponding author): isaelegbede@gmail.com
}

\begin{abstract}
Wood industries produce large volumes of residues which must be utilized, marketed or properly disposed of. Heaps of wood residues are common features in wood industries throughout the year. In Nigeria, this residue is generally regarded as waste and this has led to open burning practices, dumping in water bodies or dumping in an open area which constitutes environmental pollution. Sawmills in Nigeria generated over 1,000,000 $\mathrm{m}^{3}$ of wood waste in 2010 while about $5000 \mathrm{~m}^{3}$ of waste was generated in plywood mills. Nigeria generates about 1.8 million tons of sawdust annually and 5.2 million tons of wood wastes. The impact of improper disposal of waste wood on the environment affects both the aquatic and terrestrial ecosystems. Also burning of waste wood releases greenhouse gases into the atmosphere causing various health issues. Reuse/recycling of these wood residues in Nigeria will reduce the pressure on our ever decreasing forests, reduce environmental pollution, create wealth and employment. The literature available on this subject was reviewed and this article, therefore, focuses on the various methods of wood waste disposal and its utilization in Nigerian wood industries, the effects of wood waste on the environment as well as on human health and the benefits of proper wood waste management practices.
\end{abstract}

KEY WORDS: wood waste, sustainability, sawdust, waste utilization, wood resources

ARTICLE HISTORY: received 16 June 2016; received in revised form 28 July 2016; accepted 10 August 2016

\section{Introduction}

Compared to other resources forests have played a vital role in the development of human societies. The major marketable product of most forest is wood (timber), fuel-wood, pulp and paper, providing an estimated timber equivalent of 3.4 billion cubic meters a year globally. After a $60 \%$ increase between 1960 and 1990, wood consumption worldwide fluctuated. In the 1990s global wood consumption rose no further largely due to efficient recycling of timber and paper recycling. In 2013 the production of wood particles in the form of pellets increased by 12 percent and attained about 20 million tonnes (FAO, 2004; BAIS ET AL., 2015).

It is common knowledge that wood is the most multipurpose raw material the world has ever known. People have always relied on wood for their various needs, farming tools, building materials, fuel, weapons for hunting and warfare, until the last half of the $19^{\text {th }}$ century, wood has been virtually the most principal material used for construction and energy generation. In Nigeria, wood-based industries include timber logging, sawmilling, manufacturing of wood-based panel products (i.e. plywood, fibre board and particle board), furniture making, paper making, match making, and the manufacture of various wooden items such as tool handles, sport goods, weaving equipment and wooden toys (SEKUMADE \& OLUWATAYO, 2011).

Allied industries also make use of forest products for building, mining, packaging, leather tanning and various other purposes. Just like most natural resources used by man, timber and timber products generate lots of unwanted, or used products (waste), from tree cut-offs, sawdust, tree bark etc. and this waste (wood waste) has become prominent due to the high demand for timber and its derived products, forests are being cleared and these residues are left unattended to. Wood industries produce large volumes of residues which must be utilized, marketed or properly 
disposed of. Heaps of wood residues are common features in wood industries throughout the year. However these resources are not adequately utilized to satisfy the countries bio-resources needs and energy. These wood wastes are not well managed. This study aims to evaluate the wood waste in Nigeria in order to sustainably manage and utilize it for bio-resources and clean energy potentials. This study adopts a review-research approach, information is retrieved from publications such as journals, reports, books etc. The first section introduces the concept of wood waste with its sustainability importance, also the current state of wood waste resources in Nigeria was elaborated. The second section discusses the various attributes of wood wastes including, the various origins of wood waste, as well as characterization and classifications. The next section gives the health and environmental problems arising from these wastes. The fourth section elaborates on the various utilization strategies of the resources including energy and other sustainable and beneficial purpose. The final section includes recommendations with conclusion.

\subsection{Overview of wood waste resources in Nigeria}

The city of Lagos generates $294,979.9$ tons/year of wood waste, an estimated $2,288 \mathrm{~m}^{3}$ is generated in Abeokuta, Ogun state and $104,000 \mathrm{~m}^{3}$ is generated daily in Nigeria (Figs 1-5). In Nigeria and most developing countries in Africa, this residue is generally regarded as waste and this has led to open burning practices, dumping in water bodies or dumping in an open area which constitutes environmental pollution (DosUNMU \& AJAYI, 2002; AINA, 2006; AIYELOJA ET AL., 2013).

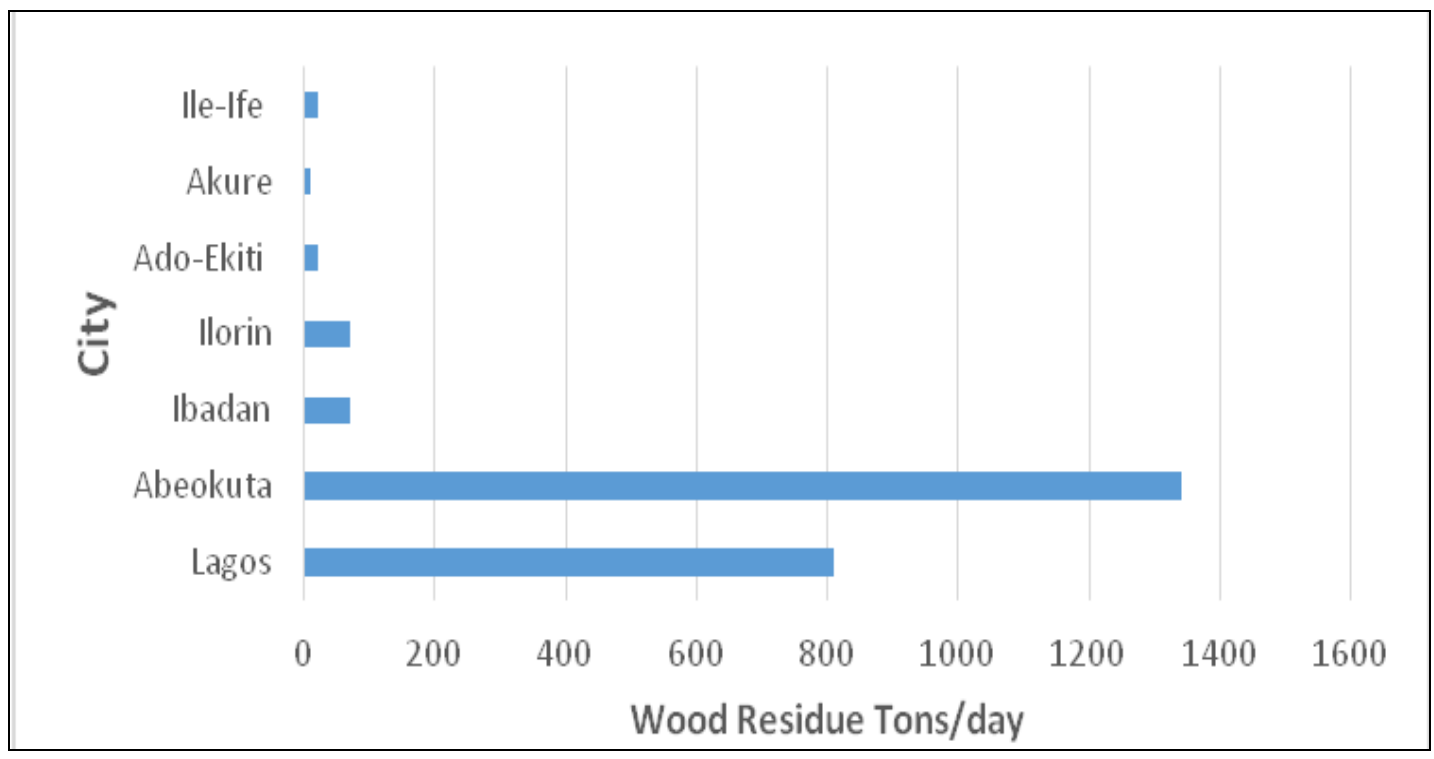

Fig. 1. Mass flow of wood waste generated in southwest Nigeria (after Oluoti et al., 2014)

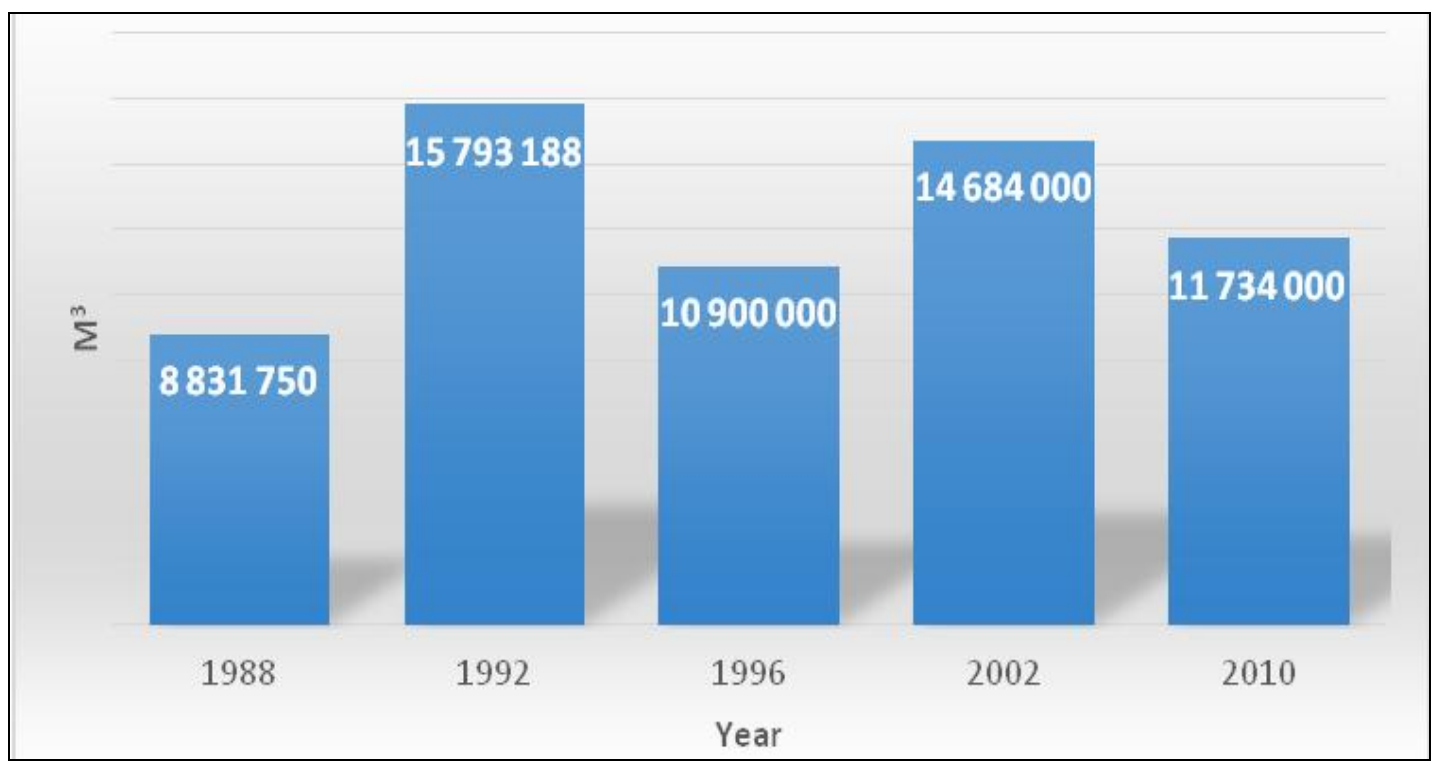

Fig. 2. Capital utilization of wood ( $\mathrm{m}^{3}$ ) in sawmills in Nigeria in the years 1988, 1992, 1996, 2002 and 2010 (after Ogunwusi, 2014) 


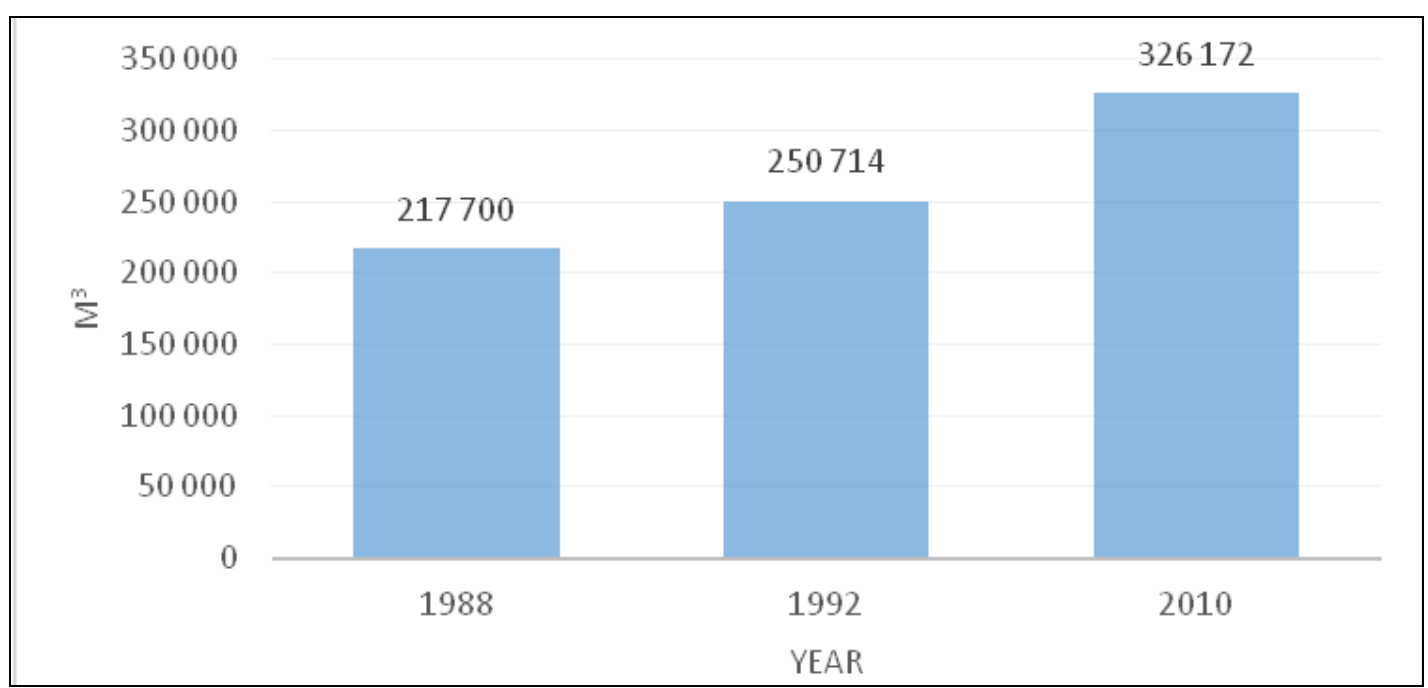

Fig. 3. Capacity utilization of wood $\left(\mathrm{m}^{3}\right)$ in the furniture industry in Nigeria (after Ogunwusi, 2014)

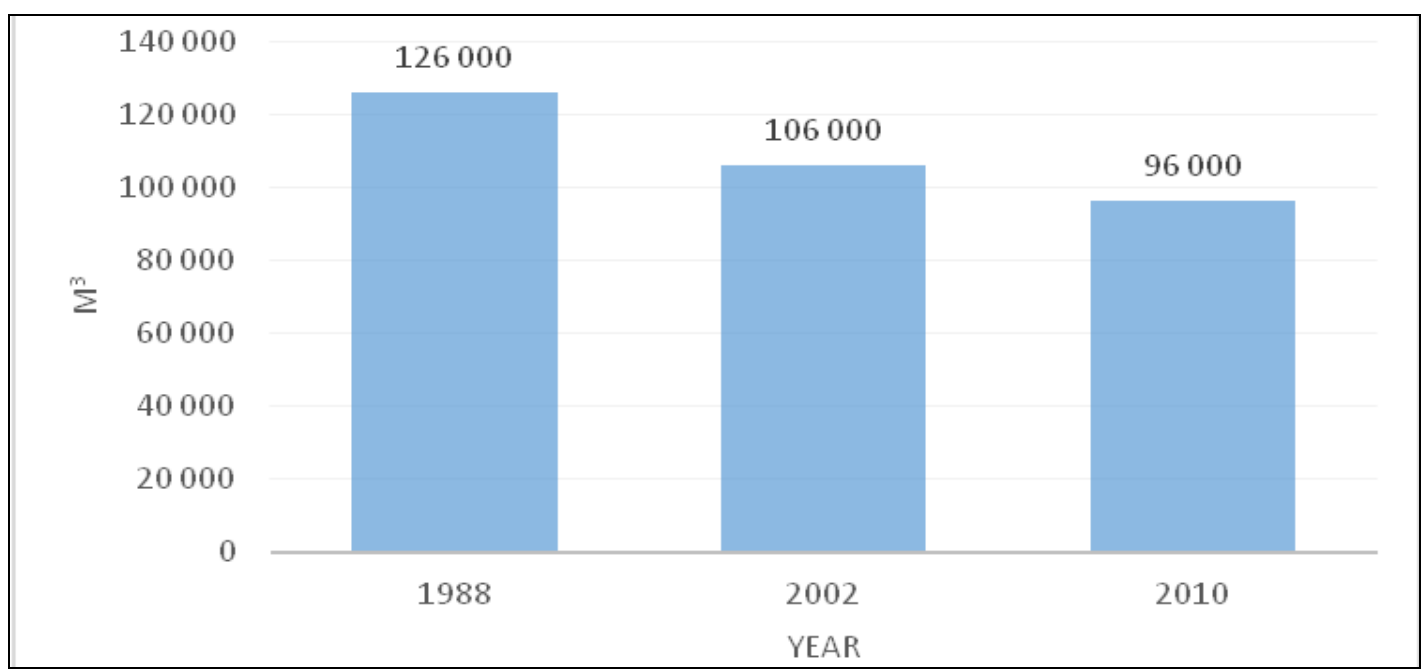

Fig. 4. Capacity utilization of $\operatorname{wood}\left(\mathrm{m}^{3}\right)$ in the plywood industry in Nigeria (after Ogunwusi, 2014)
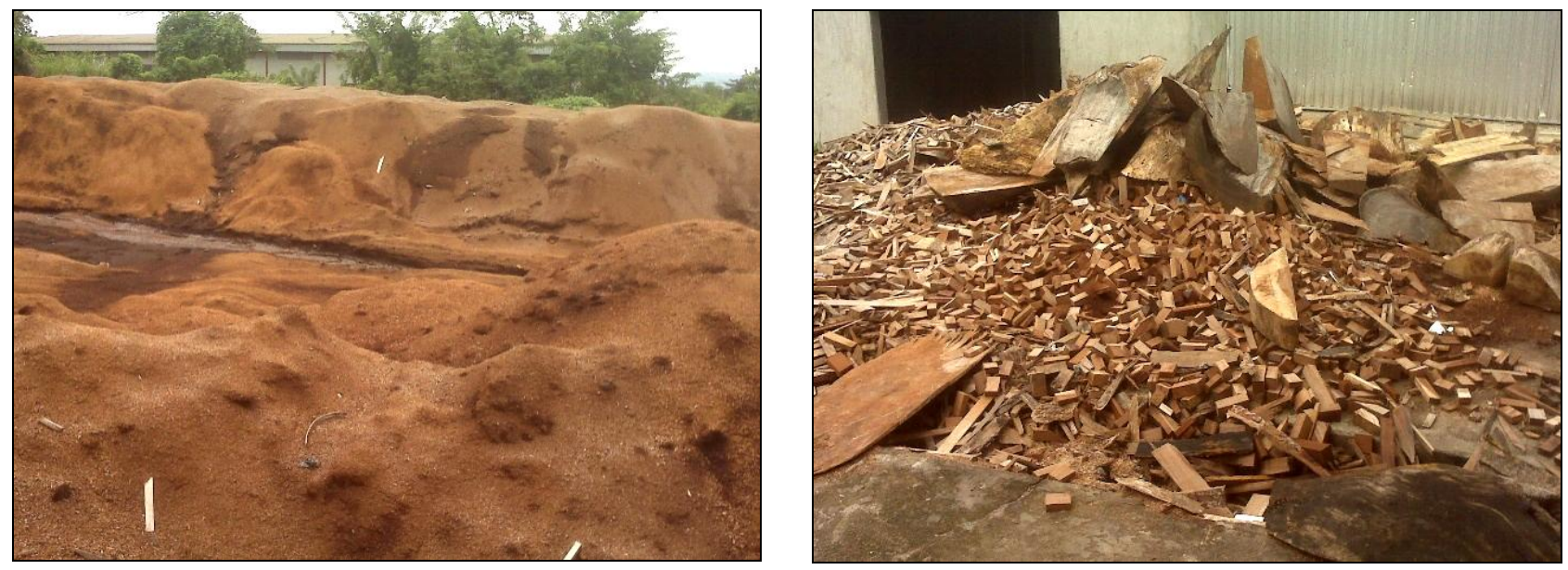

Fig. 5. Heap of sawdust and wood waste comprising of wood offcuts, wood chips and bark (left \& right) at Ire Wolede sawmill, Ilorin Kwara State, Nigeria

\section{Attributes of wood waste}

Waste could be described as any material which has been used and is no longer wanted because the valuable or useful part of it has been removed. Wastes in the wood industry could be in solid form while others are in soluble or solvent state. Waste is the left-over materials generated during the manufacturing process considered to be unusable and useful again thus and discarded. Wood wastes consists of wood pieces and particles generated from the industrial or small scale processing of wood, 
construction and demolition activities and brokendown wood products. Common wood wastes includes bark, scrap lumber, sawdust, construction and demolition wastes, offcuts, ash from the burning of wood wastes, and broken furniture (KEENE \& SMYTHE, 2009).

\subsection{Sources of wood wastes}

Wood waste is generated in various sectors of the wood industry during processing. This includes wood waste generated from sawmills, furniture industries and plywood industries as they are directly involved with the usage and conversion of timber into its derived products for consumer use. In the sawmill industry, the wood has to be converted into various sizes to maximize profit and also satisfy the demands of the people. The sawmilling industry originated in Nigeria with the establishment of the first pit-sawing facility in 1782 (AJANAKU, 2004; OGUNWUSI \& JolAOSO, 2012; ADEMOLA-AREMU ET AL., 2009). Since then, more sawmills have been established as the demand for lumber (sawn wood) continues to increase. Sawmills generate a lot of wood wastes due to the intensity of wood processing. Table 1 shows the wood wastes generated by various wood industries. Saw dusts, wood off cuts, wood backs, plain shavings, wood rejects are all wastes generated during wood processing in sawmills. Wastes such as off-cuts, sander dusts, wood shavings and wood chips are produced in the furniture industries. The plywood industries mainly generate wood waste from bark, peeler cores, veneer wastes and panel trims while the wastes from particle board industries is very negligible but comes from chip wastes from panel trimmings and dust from sanding machines.

Wood industries produce other waste that are not wood like plastic containers (which contained glue, paints etc.), waste water during the production of plywood, chemicals/preservatives, nails, paper, sacks, nylons and tin cans (OGUNBODE ET AL., 2013; CAMBERO \& SOWLATI, 2014).

Table 1. Analysis of residues generated in wood processing (after Bowyer \& Smith, 1998)

\begin{tabular}{|l|l|}
\hline \multicolumn{1}{|c|}{ Source } & \multicolumn{1}{c|}{ Type of residue } \\
\hline Forest operations & Branches, needles, leaves, stumps, roots, low grade and decayed wood, slashings and sawdust \\
\hline Sawmilling & Bark, sawdust, trimmings, split wood, planer shavings, sander dust \\
\hline Plywood production & Bark, core, sawdust, veneer clippings and waste, panel trim, sander dust \\
\hline Particle board production & Bark, screening fines, panel trim, sawdust, sander dust \\
\hline
\end{tabular}

\subsection{Classification of wood waste}

Wood waste can be categorized based on condition and category based on grade condition: Clean Wood Waste could be scrap lumber, sawmill ends, plywood, wood used in concrete with less than 2 inch diameter residual chunks of concrete on it. Clean wood may contain nails, bolts or screws in fair quantities. Clean wood waste should not have paint, oil or Styrofoam, telephone poles, treated wood, wood with tar are not considered clean wood waste. Note: wood waste that has paint or other contaminants can be recycled as construction and demolition waste. Contaminated wood waste is wood painted or coated, wood from construction, furniture, roofing planks and generally treated wood. Category based on grade: Grade A: contains wood with very few contaminants such as paint or other coverings. Mixed Grade: wood wastes with considerable amounts contaminants such as concrete and nails in relatively low quantity. Low Grade: contaminated wood containing tar and other chemicals. There are differing uses for the various grades of waste wood. Traditional uses are primarily focused on the recycling of the waste wood for use as animal bedding, equestrian use, garden mulch and utilization by the panel board industry. Despite this, the vast majority of waste wood will make its way to landfill for disposal at a cost to the construction company.

\subsection{Characterization of wood waste}

Characterization is the way in which something is described or defined. Waste characterization involves analysing different waste stream compositions and is an important part in any management of waste. New waste technology developers must take into consideration the rudiments that waste streams consist of in order to fully treat the waste (GHANI ET AL., 2013). Wood waste is usually composed of: Saw dust: produced during wood processing, Wood offcuts. Wood barks: bark is the outer most layer of wood plants, wood bark overlays the wood. Plain shavings: are wood wastes that result from smoothing or planning of wood (Figs 6-8). Wood rejects: are wood/timber that have being rejected either due to degradation or pest infestation (e.g. beetles and fungi). Wood chips: are medium sized solid materials made by cutting, or chipping, large pieces of wood (CHRISTERSSON ET AL., 2005). 

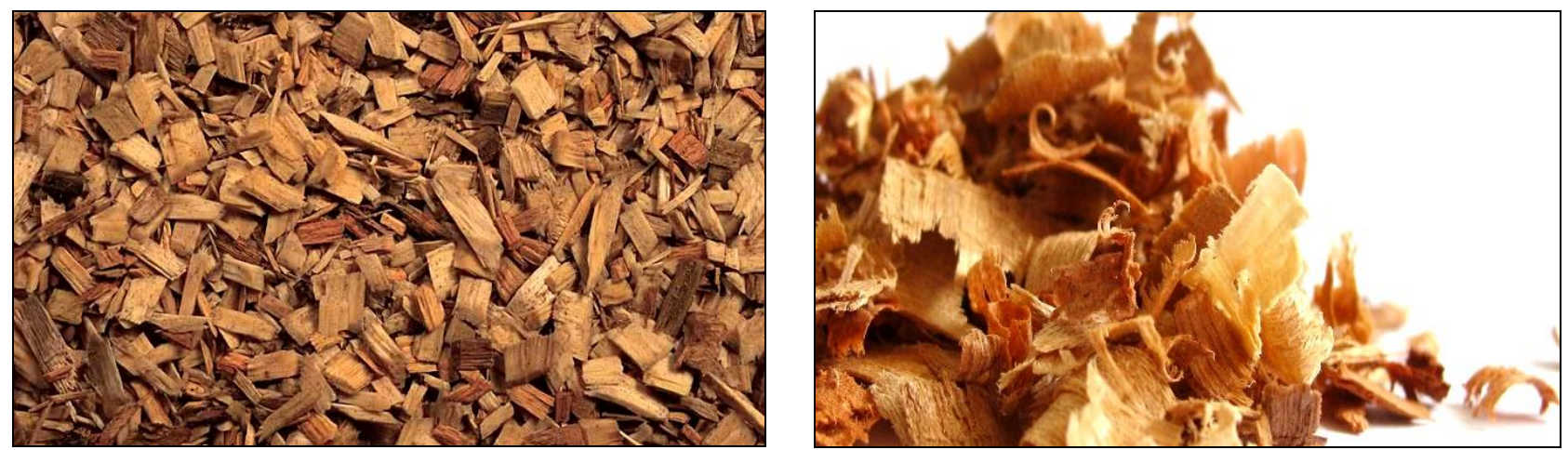

Fig. 6. Wood chips (left) and wood shavings (right)


Fig. 7. Wood bark (left) and sawdust (right)


Fig. 8. Wood offcuts (left) and wood flitches (right)

\section{Health and environmental challenges of wood waste}

\subsection{Health challenges}

Sawdust and other process dusts present a fire and explosion risk in mills. Wood waste and dust are inflammable, and if ignited can lead to fire outbreak, such a fire may cause an explosion if the volume of dust contained in the area is high. To minimize this risk, dust may be removed by manual means, or preferably, gathering by local exhaust ventilation systems and collected in bags or cyclones. The waste generated by a vertical band saw is sucked into the dust collection hood like a vacum cleaner. This reduces the sawdust in the air and ggenerates a suction pressure that sucks dust (sawdust) from the air in the wood industry (Figs 9, 10).
Workers that regularly inhale dust (wood dust) could be in danger of respiratory infection. With irritation of the respiratory tract, flu-like symptoms may occur as a result of inhaled wood dust. Prolonged exposure may lead to more serious health conditions such as asthma and emphysema. Employers must, therefore, control exposure to dust from wood. Chemicals used to treat wood if present in wood dust can cause dermatitis - red, dry, itchy skin which may develop blisters. Repeated exposures of a worker can cause severe skin reaction. Wood dust is carcinogenic, according to the International Agency for Research on Cancer (IARC). A study carried out in Canada, showed workers exposed to wood dust developed adenocarcinoma (a rare form of nasal cancer), further studies showed that workers in logging, sawmills, furniture and cabinet making, and carpentry are at an increased risk of developing adenocarcinoma (VALLIÈRES ET AL., 2015). 

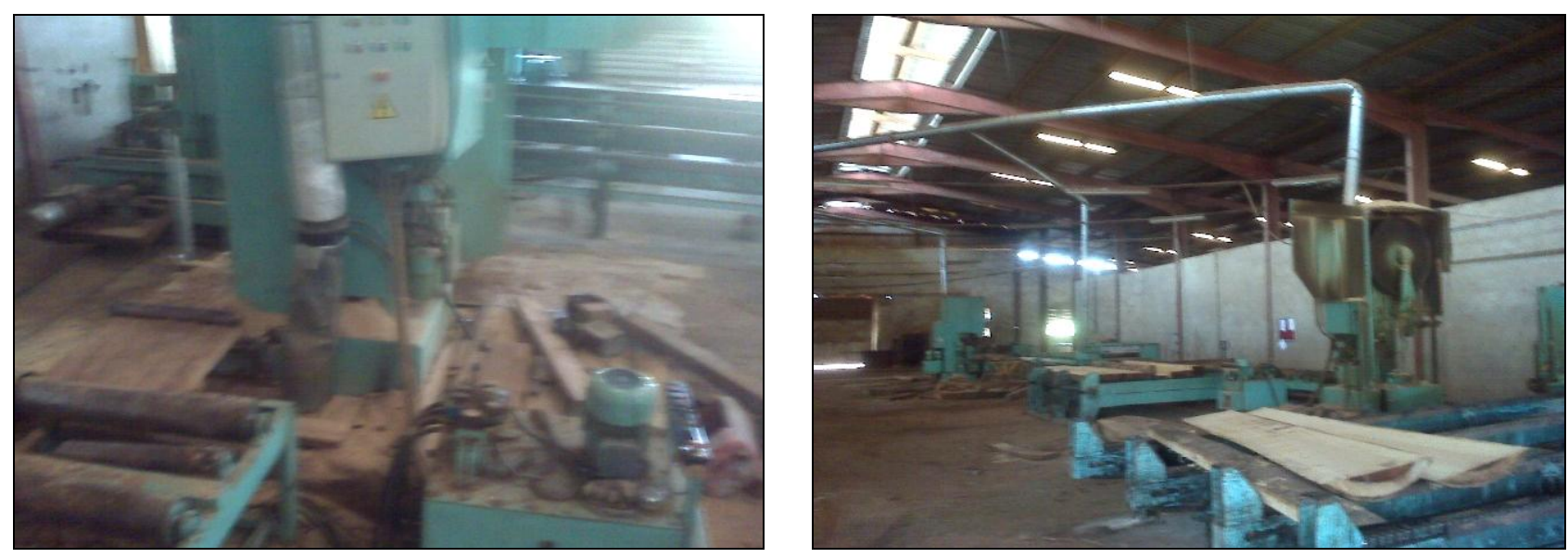

Fig. 9. Saw dust waste by vertical band saw (left) and dust collection hood (right)

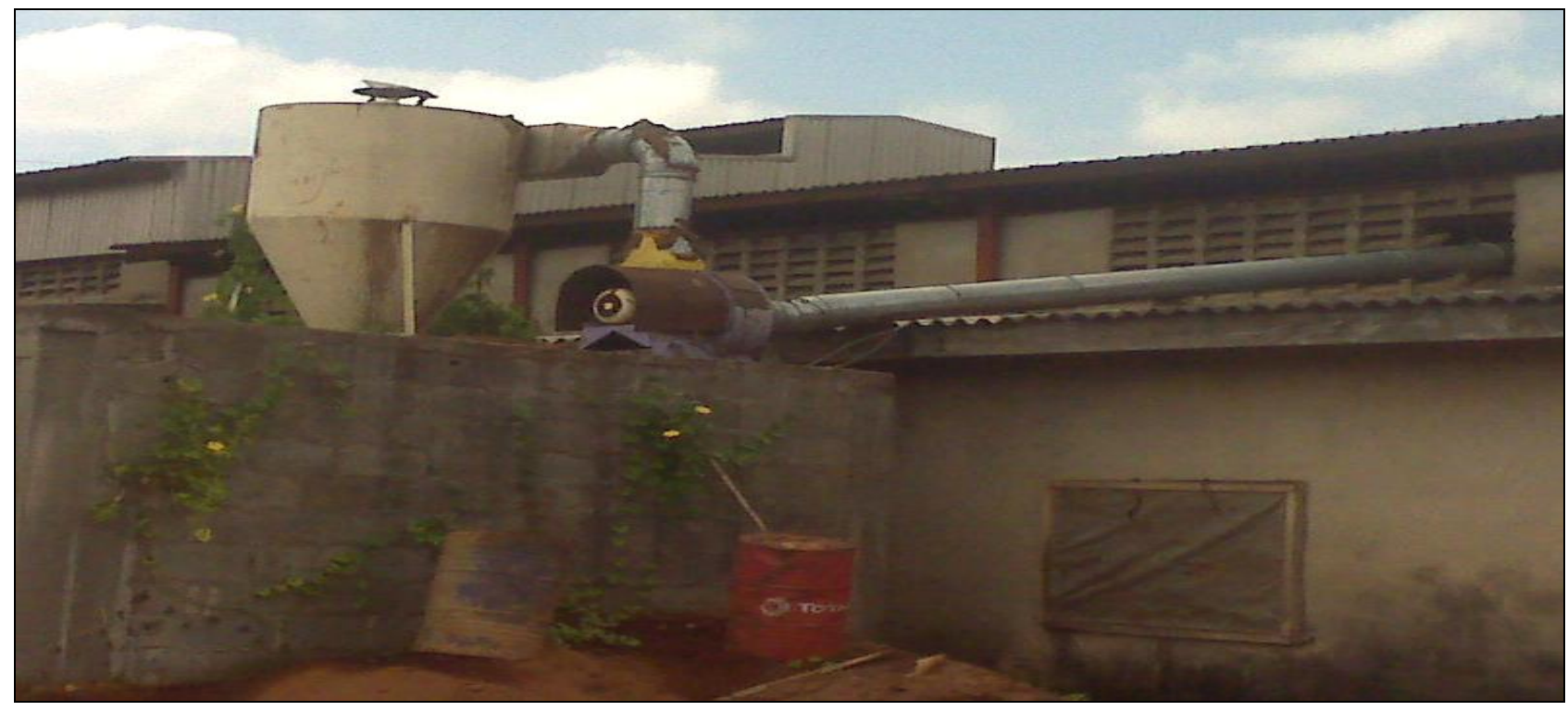

Fig. 10. Suction excavator or vacuum excavator

\subsection{Environmental challenges}

Burning of waste wood is the most common management practice in Nigerian wood industries. The burning is done in the open, releasing harmful (pollutants) substances like carbon monoxide, sulphur dioxide, nitrogen oxides, and ash into the air. Indiscriminate burning of waste wood pollutes the air, smoke contains fine particulate matter that can scar the lungs. Some chemicals in wood smoke such as polycyclic aromatic hydrocarbons (PAHs) and dioxin are suspected to be carcinogens. Wood smoke increases risk of lower respiratory infections and interferes with normal lung development in children. It can also depress the immune system and make it difficult to breathe. Another common practice by wood industries is dumping wood waste in open areas nearby. Unattended over a period of time the wood waste starts decomposing, and methane gas is emitted which is a harmful greenhouse gas. Living things must generate waste, it's associated with living; it cannot be stopped but must be managed (ODEBUnMI, 2001). Wastes pose many problems: environmental degradation, loss of aesthetic value, produce unpleasant odours and smoke pollutes air during improper incineration of wastes. If not properly disposed these could be hazardous to health; inappropriately disposed of wastes become breeding grounds for pests and vectors of diseases. Dumping of refuse (e.g. sawdust) into water bodies could block drainage and cause flooding during the rainy season, which can lead to lose of lives and properties (FAO, 1991; ELIJAH \& ELEGBEDE, 2015). An environment such as a water body contaminated by organic pollutant (wood waste) has low diversity and low species of aquatic organisms (e.g. fish) in the water body. Wood wastes dumped in rivers and lakes are toxic and clog fish gills and incidentally light penetration is reduced which limits productivity of aquatic plants. Aquatic organisms are vulnerable due to pollution of their environment, as a result of wood and other industries discharging wastes into water bodies. In developed countries, wood waste management 
practices are more elaborate than in a developing country such as Nigeria. Wood wastes are collected from various points or locations (households, factories, construction sites etc.); either directly by the process or by the individual/groups taking it (wood waste) to the processor themselves. These wood wastes are stored (if not used immediately), processed and transformed into new usable materials (FAO, 1991; ELIJAH \& ELEGBEDE, 2015).

\section{Wood resource utilization}

\subsection{Wood waste utilization}

Waste generated in Nigerian wood industries usually become pollutants which pollute the environment either due to burning or improper disposal. Over the years more advanced and improved methods of wood waste utilization have evolved. Sawdusts are used as animal beddings for poultry, in particular board making, as fuel for cooking and as charcoal briquettes. Wood industries utilize waste wood, using it in firing furnaces to raise steam and hot water. Fig. 11 shows a typical steam raising plant. Heat generated from this plant can be used domestically and industrially. Bark is sold sometimes to traditional healers or given away free of charge while slabs are disposed by selling them as firewood in local markets (KUKOGHO ET AL., 2011).

\subsubsection{Production of briquettes/pellets}

Much of the Nigerian population (about 80\%) depends on wood biomass for their domestic energy and the implication of this is high deforestation (OGUNWUSI ET AL, 2014). Briquettes are made from raw materials (such as waste wood) that are compacted into a mould, a binding agent (e.g. cassava starch) is often used to ensure the compactness. Briquettes could be in various shapes and sizes depending on the type of mould used. Briquettes have various useful applications which include household cooking and water heating, ceramics and clay ware firing for improved cooking stoves, bricks etc., fuel for gasifiers to generate electricity etc. Wood pellets are generally made from compressed sawdust, they are the most common type of pellet fuel. The use of briquettes/wood pellets will reduce the demand for wood for fuel and in turn reduce the pressure on the ever dilapidating forests (AIYELOJA ET AL., 2013).

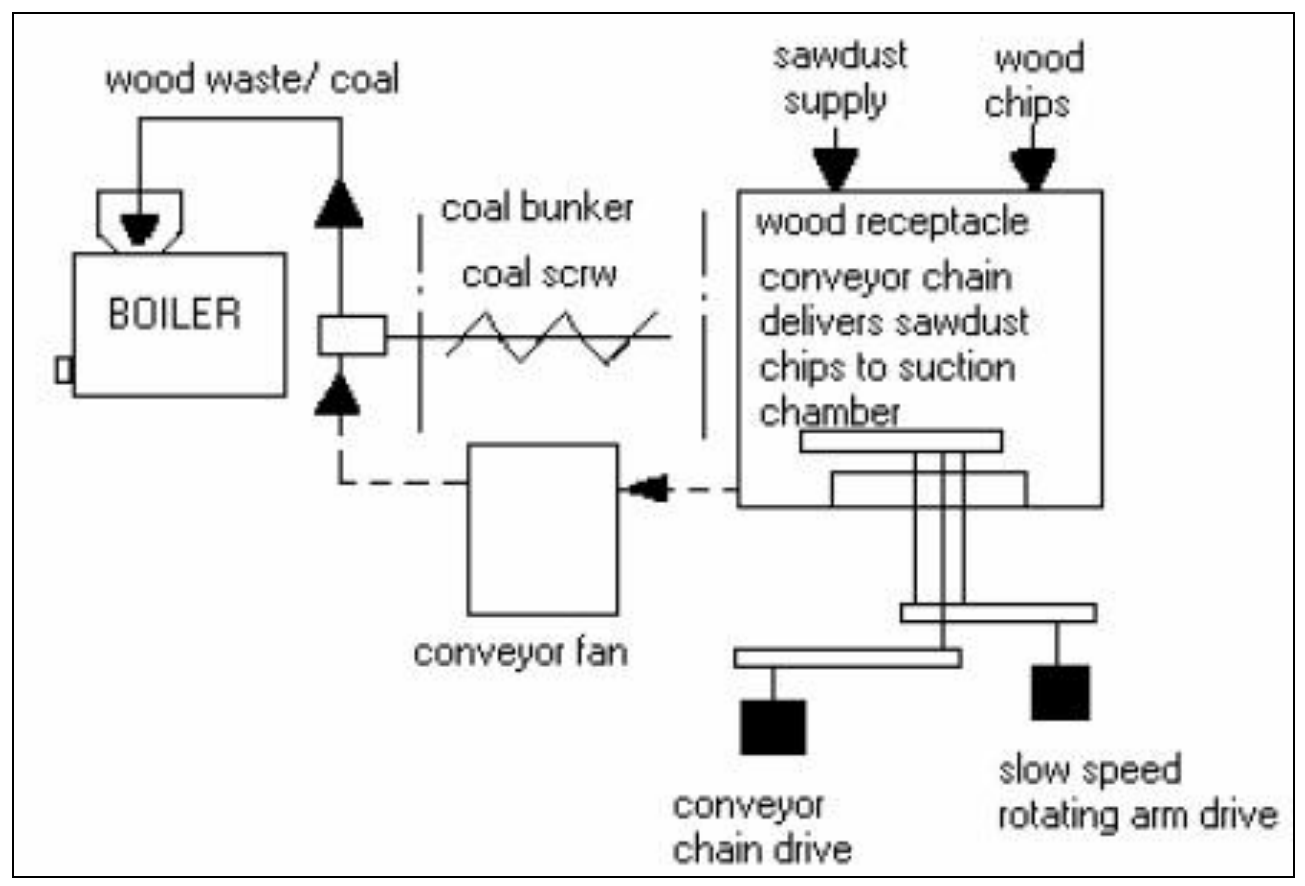

Fig. 11. A schematic diagram of a steam raising plant (Dosunmu \& AJAYI, 2002)

\subsubsection{Wood waste for energy generation}

In the rural areas of developing countries such as Nigeria, energy systems, like internal combustion engines, are used for various fixed applications, such as operation of water pumps, mills, and for electricity. Conversion of biomass wood fuel into electricity, using gasification could play a prominent role in reuse of waste wood (OLUOTI ET AL., 2014).

\subsection{Wood bark utilization}

Wood bark is an important component of hog fuel and the utilization of wood bark has not 
relished remarkable development as wood utilization (OGUNWUSI ET AL., 2014). Hog fuel is made from wood residues (wood waste such as: bark, wood chunks, sawdust etc.), then processed through a chipper or mill. The end products are coarse chips and clumps which are used as fuel. Other wood waste utilization and disposal options include: use of barkfree wood chips and other wood waste as a raw material input for the pulp and paper or boardmaking industries. Particleboard manufacturers may also accept sawdust and chips with bark. Use of wood and bark chips can be used as mulch for gardens, highway verges, and agriculture. Sawdust and wood shavings can be used for animal bedding. Wood waste can be used as a fuel to generate heat/power for the facility's space heating and process needs, and/or for export. If all other feasible, beneficial uses have been considered, wood waste should be disposed of through controlled incineration, as described below. Accumulation of waste in a dump or landfill at the sawmill is not acceptable as these options present a serious fire hazard, which once started can be very difficult to control, in addition to potential for ground water contamination (OGUNWUSI ET AL., 2014).

\subsection{Benefits of re-use/recycling}

Reuse and recycling wood can conserve natural resources. Re-use/recycling of wood/wood waste reduces the pressure on forests as this gives the forest time to regenerate and for the harvested trees to be replaced. Due to the high demand of timber and its derived products, forests are being over exploited and sometimes lost due to this practice. Forests (tress) play an important role in environmental stability, because trees aid the removal of carbon IV oxide $\left(\mathrm{CO}_{2}\right)$, a greenhouse gas which is responsible for heating the earth's atmosphere by their photosynthetic activity and oxygen $\left(\mathrm{O}_{2}\right)$ is given off as a by-product, which is in turn used by animals (including man) for cellular respiration. Reuse/recycling of trees will reduce the quantity of trees being harvested and allow trees to perform this important role. Wood waste can be used to replace coal for electricity or steam generation (ROPER, 2006; ORMONDROYD ET AL., 2016).

\section{Future outlook and recommendations}

In Nigeria like most developing countries, wood waste is generated daily due to a high demand for wood products for various uses. These wood residues have various consequences on the environment and on human health. The large quantities of wood waste residues entering the environment can be better utilized to help reduce the impact on forests and the environment due to improper disposal. Reuse of waste wood for making charcoal briquettes, in steam generating plants, to generate electricity etc., has shown prospects in developed countries, but very little in developing countries like Nigeria.

The Nigerian public should be made aware of the rapidly deteriorating forests and the consequences of this. The benefits of reuse/recycling of waste wood should be made public and encouraged as a source of wealth for small and medium sized industries. Nigeria as a developing country can benefit from this in terms of economic growth and forest resuscitation as more products can be made from this waste wood. This will also reduce the emission of pollutants (carbon II oxide and sulphur IV oxide) in to the environment, it will reduce the damage on the environment.

In Nigeria, like most developing nations proper waste management practices are lacking. Wood waste from sawmills, furniture industries and plywood industries are disposed off in a crude manner, which in most cases is either by burning or dumping in open areas which pose environmental hazards. Waste if properly managed will improve the quality of our environment, as it will reduce the amount of trees being cut and forests being lost due to the high demand/use of timber and its derived products, carbon IV oxide $\left(\mathrm{CO}_{2}\right)$, sulphur IV oxide $\left(\mathrm{SO}_{2}\right)$ emitted during burning of waste wood can be reduced to the minimum if waste wood is reduced landfill spaces can be saved as a result of reuse of waste wood, create wealth and employment. Effects of improper management of wood waste are economic loss, environmental pollution, fire hazard, delay of work and harbouring of dangerous pests and vectors.

\section{Acknowledgements}

The authors thank the researchers that assisted in the publication of this short review, and remain grateful to the editorial board for their support towards the publication of this paper.

\section{References}

Ademola-Aremu 0.0., Aina O.M., Adetiloye A.O. 2009. Levels of lead, cadmium and chromium in Oreochromis niloticus in Lagos State Lagoon. Ethiopian J. Environ. Stud. Manage., 2(3): 13-18.

Aina O.M. 2006. Wood waste utilization for energy generation. Proc. Int. Conf. Renewable Energy for Developing Countries.

Aiyeloja A.A., Oladele A.T., Furo S.B. 2013. Sustaining livelihood through sawn wood marketing in Port Harcourt, Nigeria. Int. J. Sci. Nature, 4(1): 84-89.

Ajanaku S.O. 2004. State Department of Forest, Secretariat, Chief Forestry Officer, Ibadan. 
Bais A.L.S., Lauk C., Kastner T., Erb K. 2015. Global patterns and trends of wood harvest and use between 1990 and 2010. Ecol. Econ., 119: 326-337.

Bowyer J.L., Smith R.L. 1998. Nature of wood and wood products Forest Management Development Inst., Univ. Minnesota, Self-Study Educational CD-ROM, St. Paul, Minnesota, USA.

Cambero C., Sowlati T. 2014. Assessment and optimization of forest biomass supply chains from economic, social and environmental perspectives - A review of literature. Renewable Sustain. Energy Rev., 36: 62-73.

Christersson L., Verwijst T., Amatya S.M. 2005. Wood production in agroforestry and in short-rotation forestry systemssynergies for rural development. Proc. IUFRO:s Conf. (session 12, 128), Brisbane.

Dosunmu 0.0., Ajayi A.B. 2002. Problems and management of sawmill waste in Lagos. Proc. Int. Symp. Environ. Poll. Control Waste Manage., Tunis (EPCOWM 2002): 227-228.

Elijah F.B., Elegbede I. 2015. Environmental Sustainability Impact of the Okobaba Sawmill Industry on some biogeochemistry characteristics of the Lagos Lagoon. Poult. Fish Wildl. Sci., 3: 131. doi: 10.4172/2375-446X.1000131.

FAO. 1991. African fisheries and the Environment FAO Regional Office. Accra, RAFR/91/02, Accra, Ghana: 26.

FAO. 2004. Assessing forestry project impact: issues and strategies, F.A.O. Rome: 4-6.

Ghani W.A.W.A.K., Mohd A., da Silva G., Bachmann R.T., Taufiq-Yap Y.H., Rashid U., Ala'a H. 2013. Biochar production from waste rubber-wood-sawdust and its potential use in $C$ sequestration: chemical and physical characterization. Industrial Crops and Products, 44: 18-24.

Keene S., Smyth C. 2009. End-of-Life Options for Construction and Demolition of Timber Waste: A Christchurch Case Study. Univ. Canterbury, New Zealand.

Kukogho J., Agbimien E.V., Ojo M.O., Adams B.O., Akinbosoye B.S. 2011. Assessment of wood waste generated in some selected sawmills in Kajola Local Government area of Oyo State. Contin. J. Agricultural Econ., 5 (2): 8-16

Odebunmi S.G. 2001. Solid waste transportation in Lagos state: developing a sustainable model. Ph.D. Seminar, Univ. Lagos, Lagos. Nigeria.

Ogunbode E.B., Fabunmi F.O., Ibrahim S.M., Jimoh I.O., Idowu 0.0. 2013. Management of sawmill wastes in Nigeria: Case study of Minna, Niger State. Greener J. Sci. Eng. Tech. Res., 3(2): 034-041.

Ogunwusi A.A. 2014. Wood waste generation in the forest industry in Nigeria and prospects for its industrial utilization. Civil Environ. Res., 6, 9: 62-70.

Ogunwusi, A.A., Jolaoso, M.A. 2012. Bamboo, conservation of environmental and sustainable development in Nigeria. Adv. Arts, Soc. Sci. Educ. Res., 2(9): 346-358.

Oluoti K., Megwai G., Pettersson A., Richards T. 2014. Nigerian wood waste: A dependable and renewable fuel option for power production. World J. Eng. Tech., 2(03), 234.

Ormondroyd G.A., Spear M.J., Skinner C. 2016. The opportunities and challenges for re-use and recycling of timber and wood products within the construction sector. Environmental Impacts of Traditional and Innovative Forest-based Bioproducts, Springer, Singapore: 45-103.

Roper W.E. 2006. Strategies for building material reuse and recycle. Int. J. Environ. Tech. Manage., 6(3-4): 313-345.

Sekumade A.B., Oluwatayo I.B. 2011. Economic analysis of plank production in Gbonyin Local Government Area of Ekiti State, Nigeria. Int. J. Agricultural Econ. Rural Dev., 4(1): 36-42.

Vallières E., Pintos J., Parent, M.E., Siemiatycki J. 2015. Occupational exposure to wood dust and risk of lung cancer in two population-based case-control studies in Montreal, Canada. Environ. Health, 14(1), 1. doi: 10.1186/1476069X-14-1. 